\title{
HAf
}

Volume: 9 Issue: 1 Year: 2012 doi: 10.14687 ijhs.v9i1.1978

\section{Is juvenile boot camp policy effective?}

\author{
Kübra Gültekin ${ }^{1}$, Sebahattin Gültekin ${ }^{2}$
}

\begin{abstract}
Militaristic boot camps became very popular in the U.S. in the early 1990's as an alternative to traditional prisons and probation. Less recidivism and less cost were the shibboleths of correctional boot camps. The boot camps are believed to reduce the number of repeat offenders and to lower operational costs. The rehabilitation programs and aftercare activities are thought to bring ongoing changes in inmates' behaviors. Therefore, boot camps are strongly supported by politicians and the public. Tax dollars are spent to operate the boot camps. However, despite the fact that only two decades have passed since the existence of juvenile boot camps, numerous studies have declared that juvenile boot camp prisons are ineffective in reducing future offenses of inmates, operational costs, and in continually changing the behaviors of young offenders.
\end{abstract}

Keywords: Boot camp, effectiveness, recidivism, corrections, incarceration

\footnotetext{
${ }^{1}$ Assistant Professor, Faculty of Security Sciences, Turkish National Police Academy, kgultekin@egm.gov.tr

2 Ph.D. Turkish National Police Academy Law Enforcement Training Research Center, sgultekin@egm.gov.tr
} 


\section{Introduction}

Crime is one of the most important and debated issue for several decades in the United States (Walker, 2001; Donziger, 1996). It is largely assumed that the country's crime problem is worsening throughout time (Kappeler \& Potter, 2005). Juvenile delinquency is believed to be one of the most serious problems in the nation. The media, the criminal justice system, and bureaucrats are instrumental in helping to establish the viewpoints of citizens regarding crime issues. Fear of crime has become one of the most visible characteristics in society. Citizens expect public officials and politicians to take a proactive stance to fight crime. American society expects politicians to be tough on crime. Because the majority of the American public place a high priority on fighting crime, politicians are expected to delegate amble time to deal with the issues and come up with solutions.

In the United States, first time nonviolent offenders are generally subjected to probation. Many citizens believe that this is letting criminals off too easy. Walker (2001) states that judges, in the United States, usually face two options for first time nonviolent offenders: probation and prison. On the one hand, in some cases, it is believed that prison is too severe. On the other hand, probation is considered too lenient. Critics believe that probation is neither an effective treatment nor a successful control means of criminals. It is widely accepted that a new range of punishments should be less harsh than prison but more extreme than traditional probation (Morris and Tonry, 1990).

Despite the controversy, the new range of punishments is popular within American society. The new punishments are named as intermediate sanctions, including boot camps, intensive probation supervision, home confinement, and electronic monitoring. In addition, many of the new intermediate punishments include two or more different programs. For example, intensive parole supervision may include home confinement and electronic monitoring (Walker, 2001).

The most publicized and popular intermediate form of punishment is boot camps. Boot camps are popular among politicians as well as citizens and bureaucrats because the programs are thought to be tough on criminals. They are considered a panacea to decrease the growing prison populations (Godinez, 2006; MacKenzie, Brame, McDowall, and Souryal, 1995; Poole and Slavick, 1995). Bureaucrats and policy makers show no resistance to the boot camp form of punishment and readily fund them. 
Boot camps are considered a form of shock incarceration. A military atmosphere is believed to change behaviors of young offenders and "to turn a score of lawbreakers into disciplined, authority-respecting men" (Morash and Rucker, 1990, p. 206). It is largely assumed that juvenile boot camps are an effective means to prevent repeated offenses and to decrease operational costs. Therefore, this study aims to evaluate the effectiveness of juvenile boot camps. To do so, the question whether juvenile boot camps are successful to change young inmates' behaviors; to reduce recidivism, to decrease cost; and to diminish prison population will be analyzed. This paper has two hypotheses regarding the effectiveness of juvenile boot camps. The first hypothesis is that juvenile boot camp programs cannot be effectual in reducing recidivism and changing the behaviors and attitudes of the youth because the length of the camps is too short to produce desired outcomes. The second hypothesis is the camps may decrease operational costs and prison population since the length of the programs is short compared to traditional prisons.

\section{Background}

Correctional quasi-military boot camps might be based on the American prisons of the 1820 s and 1830s because those early prisons were organized toward discipline and hard physical labor (Bottcher and Ezell, 2005; MacKenzie et al., 1995).

In the early 1980s, the belief in rehabilitation was declining, whereas the notion of 'just desserts' was an increasingly popular idea because of its harsher punishments. At the same time, the prison population was drastically increasing. Correctional boot camp programs were established because of the rising prison population (Bottcher and Ezell, 2005; Morash and Rucker, 1990). The idea was welcomed by politicians, since it was a popular policy due to bipartisan support (Simon, 1995).

A boot camp is a shock incarceration program that emphasizes a military environment. Physical training, drill, ceremony, courtesy, and strict discipline are the most fundamental and common characteristics of boot camps all around the country (Flash, 2003; Slavick, 1995; MacKenzie et al., 1995; Morash and Rucker, 1990). The control of inmates is in the hands of drill sergeants. However, intensity of militaristic approaches vary among different programs and states (Bottcher and Ezell, 2005). Some camps try to combine basic elements of military boot camps with traditional forms of rehabilitation (Morash and Rucker, 1990). 
Boot camp programs started in Georgia in 1983 with a 50-bed adult program (MacKenzie and Hebert, 1996; Poole and Slavick, 1995). However, later, boot camps were used as a solution for the growing number of juvenile offenders. The first juvenile boot camp program was established in Orleans Parish, Louisiana in 1985. Since that time, the popularity of boot camp programs for juveniles has been increasing. However, the considerable proliferation of juvenile boot camps has accelerated after the Office of Juvenile Justice and Delinquency Prevention established pilot programs in 1992 (Tyler, Darville, and Stalnaker, 2001) because pilot programs were evaluated as successful to rehabilitate the youth and to deter the future crimes. In addition, the Violent Crime Control and Law Enforcement Act of 1994 set aside funds to establish alternative incarceration methods including boot camps (Simon, 1995). Thirty-three states established some sorts of shock incarceration prison programs by 1997, most of which emphasized military style training and rehabilitation programs (Bottcher and Ezell, 2005).

Juveniles assigned to boot camps are usually first time nonviolent offenders aged 10 to 25 (MacKenzie et al., 1995; Morash and Rucker, 1990). Juveniles in boot camps are typically expected to finish the program within 90 days. However, different programs may have varying durations. After finishing the program, most of the juvenile boot camps hold a graduation ceremony in which the parents and relatives of inmates participate and certificates are given to the program graduates. A six-month to two-year aftercare programs usually follow boot camp.

In any typical boot camp, trainees are required to follow a rigorous daily schedule (Wilson, MacKenzie, and Mitchell, 2005). Military style boot camps, as Bottcher and Ezell, (2005) point out, generally consist of long daily schedules with the emphasis on physical training, military drilling, ceremony exercises, classes, group counseling sessions, and substance and alcohol abuse treatment programs. Harsh verbal direction from correctional officers, so-called drill sergeant, is common attributes of boot camps. In most boot camps, correctional officers and inmates wear military-like uniforms and use militaristic terms (see also Wilson et al., 2005; Lutze, 1998; MacKenzie et al., 1995; Simon, 1995; Morash and Rucker, 1990; Parent, 1989).

Critics believe that boot camps incorporate contradictory purposes. On the one hand, juvenile boot camps aim to deter juveniles from committing further crimes and to rehabilitate them; to punish and incapacitate on the other (Kilgore and Meade, 2004; Mackin, 1999; Clark 
and Aziz, 1996). Boot camps are expected to be cost effective. Other criticisms emerge about the likelihood that older inmates could abuse younger inmates (Morash and Rucker, 1990). It is believed that strict control of staff over inmates could lead to staff abuse of inmates (Bottcher and Ezell, 2005; Morash and Rucker, 1990; Lutze, 1998; Colman, 1994).

Today, more states are trying to implement boot camp programs. A National Institute of Justice report explains the increase of juvenile boot camps in the nation. According to the statistics, thirty-three states established more than seventy-five juvenile boot camp programs by 1997 and the number is increasing every year (Tyler et al., 2001). However, if private camps founded by local jurisdictions are taken into account, then the number becomes much higher. These escalating numbers show that it is likely that all states will adopt some sort of military style boot camps in very near future.

\section{Literature Review}

Many studies focus on and analyze juvenile boot camps. Some scholars extremely criticize boot camp programs whereas some researchers believe juvenile boot camps provide some positive outcomes. Bottcher and Ezell (2005), for example, disapprove of correctional juvenile boot camps. The authors declare that boot camps are established to reduce recidivism. They conducted research on young offenders of California's LEAD (leadership, esteem, ability, and discipline) program. However, they found no evidence that correctional boot camps reduce crime or recidivism rates.

Tyler et al. (2001) conducted research by analyzing media news and government reports about boot camps. In addition, they interviewed selected people in the Texas juvenile justice system. The researchers believe that the data that has been derived is not sufficient to make definitive decisions. However, the costs and recidivism rates are relatively disappointing despite some positive results. In contrast to public perception, boot camps are not very efficient to rehabilitate young offenders. According to researchers, military style boot camps for juveniles are not an appropriate answer to the growing problem of juvenile delinquency. Juvenile boot camp programs are very popular not because they work effectively but because they have an attractive public appeal.

Juvenile boot camps are usually addressed for criticism. Morash and Rucker (1990) conducted research on boot camps by analyzing prior research and criticized militaristic programs since they believed that military style boot camp programs are full of inconsistent philosophies, policies, and procedures. The researchers believe that inmate aggression is 
increased throughout camp training, which affects after-camp lives of juveniles by promoting aggressive behavior

In addition to increased aggression, as Lutze (1998) believes that juvenile boot camps cause other negative outcomes such as lower self-esteem and emphasized male-sex role stereotype. According to the author, juvenile boot camp programs do not differ from traditional prisons with regard to rehabilitative concerns. Although boot camps provide external control, including safety and discipline for juveniles, they lack of emotional feedback that provides internal control. Without internal change and growth, it is almost impossible to rehabilitate offenders. However, the researcher emphasizes, juveniles feel safer in boot camps than traditional prisons.

Simon (1995), in his article They Died with Their Boots on: the Boot Camp and the Limits of Modern Penalty, states that boot camp programs are very costly not only because of direct costs of camps and aftercare program but also because of indirect cost that occurs due to increasing likelihood inmates commit new crime after being released. The author emphasizes that the current form of boot camp will not remain for long despite it is political appeal.

This study analyzed existing research to find answers for the stated two hypotheses. The main resources are numerous studies and scholarly journals. A literature review was done to clarify the supporting and opposing data concerning juvenile boot camps. Similarly, governmental reports were used to enhance the arguments. The effects of boot camp implementation in different states have been examined, and implementation problems have been stated. Finally, recommendations are stated to highlight possible solutions to improve the effectiveness of juvenile boot camps.

\section{Findings}

\section{a. Recidivism}

One of the fundamental goals of juvenile boot camp programs is to prevent repeat crime (Marcus-Mendoza, Klein-Saffran, and Lutze, 1998; Poole and Slavick, 1995). Recidivism rates for graduates of juvenile boot camps are difficult to measure because of several limitations. Tyler and his colleagues (2001) state that the first problem in assessing recidivism rates is the definition of recidivism itself (see also MacKenzie et al., 1995). Many studies espouse different criteria for recidivism and this makes measuring recidivism complicated. Second, juvenile boot camps are relatively new programs and there affects on 
recidivism is unknown. Third, the ages of inmates are declining. When juvenile camps were first started, the age range was 15-18. However, offenders as young as 10 years old are currently in juvenile boot camps. These factors make recidivism research difficult to conduct.

Existing literature shows that recidivism rates of juvenile boot camps are discouraging (Wilson et al., 2005; Bottcher and Ezell, 2005; Tyler et al. 2001; Lutze, 1998; Simon, 1995; Poole and Slavick, 1995; Colman, 1994; Morash and Rucker, 1990). Some say that boot camps make no difference on recidivism (Wilson et al., 2005), while some researchers state that recidivism among juvenile boot camp participants is higher than that of traditional prisons (Flash, 2003). For example, the recidivism rate of boot camp graduates is around seventy-two percent, whereas the ratio of released inmates of traditional detention centers is around fifty percent in Cleveland, Ohio. Similar results, which indicate boot camp graduates have high recidivism rate than that of other prisons, have been found in Denver (Flash, 2003).

Parental control can also affect juvenile recidivism. Tyler (2001) claims that some parents tell boot camp administrators that they do not want their child to return home. They say that the state can do whatever it wants. Moreover, some parents even do not come to the courtroom for their kids' trials. Those parents do not support their children. Without parental support, the juveniles are more likely to commit crimes. Therefore, parents play key roles in preventing recidivism of juveniles.

\section{b. Cost}

Boot camp programs, despite public belief, are not cost effective (Poole and Slavick, 1995). Legislatures are willing to spend more money for juvenile boot camps despite comparatively low number of inmates. For example, a boot camp in North Texas has a 20,000 square foot facility serves for only 40 inmates (Brewer in Tyler et al., 2001). According to the Koch Crime Institute, an average boot camp spends $\$ 93$ per a day per a juvenile offender; nevertheless, the cost may drastically increase in some states. For example, some facilities spend $\$ 188$ per a day per a juvenile. It seems that the average yearly cost per juvenile boot camp resident is more than $\$ 33,000$, whereas the annual cost of an inmate in a detention center is around $\$ 31.000$ (Tyler et al., 2001). Juvenile boot camps are more expensive than traditional juvenile correctional institutions even though the lengths of the boot camps are much shorter than usual incarceration services.

On the other hand, the juvenile boot camps are far more costly than juvenile probation, including intensive probation. Even they are an expensive means of controlling 
growing juvenile crime problem. Surprisingly, the Office of Juvenile Justice emphasizes that average boot camp programs are ten times more costly compared to probation (Tyler et al., 2001). Thus boot camp programs are not cost effective even though lengths of juvenile boot camps are shorter than traditional sentencing methods.

\section{c. Participants}

Juvenile boot camp programs differ in the selection procedures of inmates (Simon, 1995). Juvenile boot camp programs are generally not voluntary. Most young offenders are sent to boot camps by the courts, corrections department and parole commissions (MacKenzie, 1990). Some boot camp programs may even accept voluntary participants. However, if any trainee fails, then he has to go to traditional prison to serve his time (Lutze, 1998; Parent, 1989). Eligibility criteria for participants may vary programs to programs and states to states, though usually nonviolent and first time offenders are accepted. For example, a program that is administered by the California Youth Authority specified that only nonviolent juvenile over the age of 14 with parental consent, medical clearance, and Youth Offender Parole Board approval could participate in the program (Bottcher and Ezell, 2005).

\section{d. Aftercare}

Generally an aftercare program is pursued after offenders are released because it is believed that aftercare activities are important to make boot camp programs effective (Bottcher and Ezell, 2005). It is believed that an effective aftercare program causes a decrease in recidivism (Flash, 2003; MacKenzie, et al., 1995). However, it seems that aftercare activities do not get enough attention from boot camp program administrators since aftercare actions are left to overworked juvenile parole and probation officers (Brewer, in Tyler et al., 2001). It is impractical to expect successful aftercare from overworked officers. Therefore, it is hard to say that aftercare is effective.

Some graduates of juvenile boot camps report to officials that their peers make fun of their appearance and attitudes when they return home (Landers, in Tyler et al., 2001). This can be understandable because released graduates mostly return to their pre-camp environments and life styles. Therefore, aftercare efforts should try to provide a different setting for inmates after being released. If aftercare officials can disconnect the interaction between the juvenile and pre-camp atmosphere, the chance of success of boot camp programs is likely to increase considerably. 
Another aftercare problem, according to the Office of Juvenile Justice and Delinquency Prevention (OJJDP), is the discouraging results of juvenile boot camps regarding recidivism rates due to lack of constancy and coordination in the aftercare programs. Therefore, improving coordination among aftercare efforts will increase effectiveness of the boot camps program.

\section{e. Diversity of Programs}

Juvenile boot camps differ in many aspects. Some of camps adopt a strict military model with the emphasis of heavy physical activity and discipline, while others implement more rehabilitative and educative programs (Morash and Rucker, 1990). In addition, there are some other differences among juvenile boot camps programs. For example, the background of juvenile offenders accepted into programs, age of juveniles, the length of the programs, costs and aftercare activities may differ program to program and state to state.

Juvenile boot camps vary in cost, size, style, inmates, staff-to-inmate ratio, and their focus (Marcus-Mendoza et al., 1998). As stated above, the cost per inmate differs among juvenile boot camps. The range starts from $\$ 65$ per inmates in Alabama and goes to $\$ 188$ per youth in New Jersey. An average yearly cost per juvenile camp attendee is more than $\$ 33,000$ with in the country (Tyler et al., 2001). The costs of some programs might be much higher than this, whereas some might have lower costs.

Similarly, facility sizes differ significantly among states and programs (Bottcher and Ezell, 2005). Some camps are established on very large grounds, while others have limited space. The size differences should be also taken into consideration when assessing the effectiveness of juvenile boot camps since the size affects activities within each camp. The length of camp programs differs between camps (Tyler et al., 2001). Some of juvenile boot camps have thirty-day programs, while others have nine-month programs (Simon, 1995).

In addition, styles of boot camps vary with some focusing on physical activities and discipline, some concentrating on counseling, and others centering on vocational training (MacKenzie, et al., 1995). Similarly, characteristics of inmates are diverse. Some camps only accept first-time nonviolent offenders, voluntary participants, or court ordered inmates.

Another important difference among juvenile boot camp programs is the type of supervision program provided for inmates after their graduation (MacKenzie, et al., 1995). Traditional probation supervision is used for some graduates and others receive electronic monitoring. 


\section{f. Effects of Juvenile Boot Camps on Prison Population}

It is assumed that juvenile boot camps are an effective solution for overpopulated prisons because the time spent in camps is much shorter than traditional incarceration facilities. However, boot camp prisons only serve a relatively small number of youth. Therefore, juvenile boot camps are not a remedy for overpopulated prisons in the US. Primary research shows that boot camp programs decrease the prison population one percent to two percent while prison population increase five percent to ten percent. Therefore, it can be easily concluded that boot camp programs are not a remedy for overpopulated prisons all around the nation.

\section{Discussion}

Most of the juvenile boot camp programs consist of three main components; militarystyle drill with strict discipline, rehabilitative activities, and educational/vocational programs. The majority are military-style drill with a strict disciplinarian approach (Lutze, 1998; MacKenzie and Hebert, 1996; MacKenzie, et al., 1995). Supporters of the juvenile boot camp programs believe that "the general idea of boot camps is to motivate delinquents to reform" (Tyler et al., 2001, p. 449). However, it is controversial whether military style approaches can succeed in reforming juvenile offenders. Military behavior may not be appropriate because harsh methods can be physically and psychologically harmful for young inmates. The inmates usually have to follow a strict schedule everyday. They get up very early and go to bed very late. They are expected to be very tidy. For example, if an inmate does not tidy up his bed, he is punished by the drill sergeant. The current programs of many juvenile boot camps seem punitive rather than rehabilitative.

The lengths of boot camps program are a problem because it is difficult to change juveniles' lives in a few short weeks (MacKenzie, et al., 1995). Some believes that young inmates must undergo longer boot camps programs to bring about lasting positive change (Tyler et al., 2001). Boot camp graduates most probably will return to their prior environment, and this return could provide opportunity for them to commit additional crimes. Therefore, it is hard to change the inmates' attitudes and perceptions without a long-term bringing about long-term and lasting change.

Although many camps are very structured, it does not prevent the victimization of inmates. The younger inmates are under danger to be victimized by older juveniles. In addition, the staff of camps can easily abuse the inmates. Various scholars (see Bottcher and 
Ezell, 2005; Tyler et al., 2001; Styve, MacKenzie, Gover, and Mitchell, 2000; Morash and Rucker, 1990) state numerous examples about the victimization of inmates.

In addition, the focuses of juvenile boot camps change considerably. Some focus on counseling, some focus on vocation, some concentrate on punishments, and some center on military discipline. Therefore, this diversity affects any evaluation regarding juvenile boot camps because the focal points of facilities affect their effectiveness. This may be evidence that programs try to customize their curriculum according to the needs of inmates. Second, it may indicate that the juvenile boot camps program administrators do not know what works best.

The parental support is also very important to enhance the positive affects of juvenile boot camp programs. A supportive family makes the chance of positive outcomes higher. On the other hand, an inmate who is forced by his parents to boot camps is less likely to get positive values from boot camp experiences.

On the other hand, the analysis of boot camps as a policy choice shows that the idea establishing juvenile boot camps can be rooted to rational choice theory. This is so because rational choice theory provides an opportunity to make decisions according to previous experiences and evidences. Similarly, rational choice theory involves "systematic evaluation of options through an analysis of the various consequences of the judgments made such as validity, rationality, value assessment and risk aversion" (Masri, 2003). When the idea of intermediate sanctions arose, there were several alternatives including boot camps, electronic monitoring, home confinement, and intensive probation supervision. Among them, boot camp policy became more popular. Juvenile boot camps policy has been adopted because it is believed that military style training and strict disciple can reshape the youth since it is previously experienced that the members of the Army become more disciplined, law-abiding, and respectful to others after entering the military service. The personalities of the soldiers are reformed with the entering army forces. Therefore, military style drilling and discipline are supposed to redesign juvenile delinquents. Boot camp policy is a rational choice for the public and politicians because it assumed that boot camp policy would save money and time spent for juveniles. In addition, it is believed that boot camps will also rehabilitate and change the attitudes of inmates. It seems that all expectations of public, bureaucrats, and politicians from boot camps are rational and experienced by the Army. Obviously, it can be concluded that juvenile boot camp policy was sourced from rational choice theory. 


\section{Does the Juvenile Boot Camp Policy Have Potential to Succeed in Turkey?}

More than $20 \%$ of all offenders in 2009 are under the age of 25 in Turkey (TÜIK, 2011; see also Içli, Altay, Başpınar ve Bahtiyar, 2011). Therefore, Turkey needs particular policies to deal with this notion of juvenile delinquency. Can boot camp policy be an effective approach? Does it have potential to lead positive results in juvenile delinquency and problems of corrections in Turkey? On the one hand, boot camps, in theory, can be considered as a plausible policy. Hypothetically, boot camps seem to be a panacea for many problems. However, results of the policy implementations seem discouraging. It involves in many unanticipated results and disappointing outcomes. By looking at existing research and current implementations, one might argue that boot camp policy is not an effective strategy for Turkish Criminal Justice System because of a number of reasons. First, research shows that boot camp policy has not been successful to prevent or reduce recidivism (Parent, 2003). Some research even claims that it causes increase in recidivism rates. One of the main goals of the policy was to be an effective solution on recidivism; however, the policy seems to be failed preventing recidivism. Second, findings indicate that current implementations of boot camps are punitive not rehabilitative even though the policy is expected to rehabilitate the young offenders (Marcus-Mendoza et al., 1998). The military approach, indeed, does not seem to be promising in rehabilitating offenders since many psychological and sociological problems arise among the members of military. Harsh methods in military style training can cause physical and psychological harm on prisoners. That is to say, boot camps can be harmful for young inmates (Tyler et al., 2001). Obviously, military style boot camp is not very promising in rehabilitation of delinquent juveniles.

Third, after the military style camps, inmates are likely to go their pre-camp social environment. These social environments provided opportunity for delinquent acts or lead to crime. Returning pre-prison environment is likely to make same effect on ex-convicts. Unless the inmates are given different opportunities and different social settings, the impact of boot camps will be temporary. Fourth, boot camps do not succeed preventing victimization of prisoners. Young inmates can be victimized by older ones and by facility staff. Recent Pozant1 prison facility case shows that unfair treatment of young inmates is an issue in Turkey's correctional facilities (Hurriyet, 2012). Sadly, boot camp policy is not found to be successful in preventing victimization of young inmates. Fifth, present implementations have varying focuses in facilities (MacKenzie, et al., 1995). There seems confusion about what 
boot camps are for. This obviously affects their success. Perhaps, these camps want to accomplish too many things but achieve too few. This lack of a widely agreed focal point makes it difficult to be successful in Turkey. Sixth, existing research shows that boot camp policy is not cost effective. On the contrary, need for new and well-trained personnel and training costs may bring additional spending to current expenditures. Implementing boot camp policy is not reasonable for cost-saving purposes. Finally, boot camps does not seem to be an effective solution to prison over-crowding since it is practically very difficult to train all inmates and rehabilitate them. Accordingly, it does not have potential to be a solution for prison over-crowding in Turkey.

On the other hand, some adjustment can make the impact of the policy differ in Turkey. For example, changing the current punitive stance of the program toward rehabilitation can be a valuable adjustment to make the policy provide desired effects since the current implementation does not seem to reduce recidivism. Turkish public administration has a central structure and can effectively overcome varieties in implementation and changing focuses of facilities. However, this same central structure makes it difficult, if not impossible, to make adjustments in curriculums according to variations in the needs of juveniles. Boot camps usually accept non-violent first-time offenders. Since non-violent juveniles are gathered in the same facility they feel safer. Turkish correctional facilities can be strict on accepting non-violent first-time young offenders and reject violent ones and criminals with previous criminal records in addition to age limitations. Such implementation is likely to yield more positive results in rehabilitation and preventing abuses. In addition, family bonds are stronger in Turkish community compared to the U.S. Research indicates that parental support is vital to be successful, particularly in rehabilitation of inmates. A carefully established boot camp program and aftercare programs with supports of juveniles' families tend to lead desired outcomes since current disappointing results, to some extent, emerge due to lack of commitment from families.

Consequently, the current implementations in the U.S. do not seem to be promising for Turkey. Research shows that boot camp policy has not been successful in many aspects. However, it does not mean that the policy will not work in Turkey. If some major adjustments are made and problematic aspects of the policy are revised or replaced with a new and focused philosophy, it may provide expected outcomes in Turkey. Particularly, 
family support in Turkey can be an effective aftercare instrument to prevent recidivism and to rehabilitate inmates in the long run.

\section{Recommendations}

The purposes of juvenile boot camps is to rehabilitate young offenders, but current programs are punitive rather that treatment oriented (Marcus-Mendoza et al., 1998). Education and rehabilitation should be emphasized more than punishment functions. An emphasis on education may cause a decrease in recidivism among program graduates.

The focus of the camps should be changed from punitive stance, since it is clear that punitive programs do not reduce recidivism. In addition, boot camps and aftercare programs should address family problems so that a new bond can be generated between the parents and the program graduates.

Trends show that juvenile boot camps will continue to increase and large amounts of tax dollars will be spent on their operation. Therefore, more careful and focused analyses should be done and future research should try to determine what works and what does not work. Moreover, the best practices of boot camps should be studied and replicated to increase consistency and increase the chance of success of other boot camp programs. Successful boot camps will return responsible and law-abiding youth to the community.

\section{Conclusion}

A twenty-year period has passed since first boot camp program was established, and more than a decade has been passed since the enormous explosion of boot camp facilities within the country. Making a meaningful conclusion regarding the effectiveness of juvenile boot camps is problematic because more time and studies are needed. Even though it is problematical to make conclusions concerning boot camps, some tentative conclusions can be derived from existing studies.

An investigation by the U.S. Department of Justice in 1998 shows that juvenile boot camps are not effective in reducing recidivism rates. Boot camps, in addition to being ineffective, may also be harmful for juveniles (Tyler et al., 2001). The camps are unsuccessful at decreasing recidivism rates because it is difficult to quickly change behaviors that have taken a life time to develop. For example, boot camps teach self-discipline and selfcontrol that many of inmates never had. Even though inmates in boot camps seem accommodating, the change in inmate behavior is often temporary. Therefore, more time is needed to turn juvenile delinquents into law-abiding individuals. 
Gültekin, K., Gültekin, S. (2012). Is juvenile boot camp policy effective?. International Journal of Human Sciences [Online]. 9:1. Available: http://www.insanbilimleri.com/en

On the other hand, it should be noted that, despite staff abuse and pressure from older other trainees, inmates feel safer in boot camps than ordinary prisons (Styve et al., 2000; Lutze, 1998). Most of the inmates are nonviolent offenders, and this fact makes juveniles feel safer. This concern is important for younger inmates because rapes, assaults, physical violence are common issues in traditional prisons. In addition, boot camps are very structured and provide stable, predictable environments, but more than that is needed for effective rehabilitation (Lutze, 1998). Effective rehabilitative includes therapeutic programs that focus on reintegration into the community (Styve et al., 2000).

Juvenile boot camps do not lessen costs or reduce recidivism, are not successful at changing the behaviors of the inmates. Therefore, our first hypothesis, that juvenile boot camp programs are not effective in reducing recidivism and changing the behaviors and attitudes, is tentatively proven. Similarly, boot camps do not solve overpopulation of prisons since they serve for only a small number of youth. Even though, boot camps seem to reduce costs, aftercare activities greatly increase program costs. Therefore, boot camps do not lessen operational costs. Hence, our second hypothesis is not proven.

\section{References}

Bottcher, J. and Ezell, M. E. (2005). Examining the effectiveness of boot camps; a randomized experiment with a long-term follow up. Journal of Research in Crime and Delinquency 42(3), pp. 309-332.

Clark, C. L., \& Aziz, D. W. (1996). Shock incarceration in New York State: philosophy, results, and limitations. In D. L. MacKenzie \& E. E. Hebert (Eds.), Correctional Boot Camps: A Tough Intermediate Sanction. Washington, DC:National Institute of Justice.

Colman, A. (1994, Spring). WA and 'boot' camps. Youth Studies Australia 13 (3).

Colman, A. (1994, Winter). 'Boot' camps. Youth Studies Australia 13(2).

Donziger, S.R. (1996). The real war on crime: the report of the National Criminal Justice Commission. New York, NY: HarperCollins Publishers, Inc.

Flash, K. (2003, December). Treatment strategies for juvenile delinquency: alternative solutions. Child and Adolescent Social Work Journal, 20 (6), pp.509-527.

Godinez, T. (2006). Perceived effects of correctional boot camps on juvenile delinquents: attitudes of correctional personnel toward the effectiveness of correctional juvenile boot camps and recidivism. Online article. Retrieved April 14, 2006 from http://www.poetrycircle.org/research.php.

Hurriyet (2012). Rapor: Kötü Muamele ve ihmal. Downloaded from www.hurriyet.com.tr on March 23, 2012.

Içli, T. G., Altay, A., Başpınar, T., and Bahtiyar, M. (2011). Türkiye'de Hükümlü Profili: Sosyal, Kültürel ve Ekonomik Özellikler. Ankara: Polis Akademisi Yayınları 
Kappeler, V. E. and Potter, G. W. (2005). The mythology of Crime and criminal justice (5th $e d)$. Long Grove: IL, Waveland Press.

Kilgore D., and Meade, S. (2004). "Look What Boot Camp's Done for Me:" Teaching and Learning at Lakeview Academy. Journal of Correctional Education, 55(2), 170185.

Lutze, F. E. (1998). Are shock incarceration programs more rehabilitative than traditional prisons? A survey of inmates. Justice Quarterly 15 (3), pp. 547-566.

MacKenzie, D.L. and Hebert, E.E. (1996). Correctional boot camps; a tough intermediate sanction. National Institute of Justice Report.

MacKenzie, D. L., Brame, R., McDowall, D., and Souryal, C. (1995). Boot camp prisons and recidivism in eight states. Criminology, 33(3), 327.

MacKenzie, D. L.(1990). Boot camp prisons: components, evaluations, and empirical issues. Federal Probation, 54 (3).

Masri, L. (2003). Rational Chice Retrieved May 2 from http://wwwpersonal.umich.edu/ lmasri/rational_choice_theory.htm

Mackin, J. (1999, Winter). From boot camp to monastery. Human Ecology Forum, 27 (1). pp.3-5.

Marcus-Mendoza, S. T., Klein-Saffran, J., and Lutze, F. (1998). A feminist examination of boot camp prison programs for women. Women \& Therapy, 21(1), 173-185

Morash, M. and Rucker, L. (1990). A critical look at the idea of boot camp as a correctional reform. Crime and Delinquency 36(2), pp.204-222.

Parent, D. G. (2003). Correctional Boot Camps: Lessons from a decade of research. Report for National Institute for Justice, NJC Number: 197018.

Poole, C. and Slavick, P. (1995). Boot camps: a Washington state update and overview of national findings. Online article. Retrieved April 14, from http://www.wsipp.wa.gov/rptfiles/bootcamp.pdf

Simon, J. (1995). They died with their boots on: the boot camp and the limits of modern penalty. Social Justice, 22(2), p.25.

Styve, G. J., MacKenzie, D. L., Gover, A. R., and Mitchell, O. (2000). Perceived Conditions of Confinement: A National Evaluation of Juvenile Boot Camps and Traditional Facilities. Law and Human Behavior, 24(3), 297-308.

Türkiye İstatistik Kurumu (TÜİK). (2011). Turkey in Statistics 2011. Downloaded from www.tuik.gov.tr on March 23, 2012.

Tyler, J., Darville, R., and Stalnaker, K. (2001). Juvenile boot camps: A descriptive analysis of program diversity and effectiveness. Social Science Journal, 38(3), pp.445-460.

Walker, S. (2001). Sense and nonsense about crime and drugs: A policy guide. Belmont, CA: Wadsworth/Thompson Learning.

Wilson, D. B., MacKenzie, D. L., and Mitchell, F. N. (2005). Effects of correctional boot camps on offending. Retrieved Aprill4, 2006 from http://www.campbellcollaboration.org/doc-pdf/Wilson_bootcamps_rev.pdf. 